\title{
Epidemiologia dos Idosos com AIDS na Bahia segundo o SINAN de 2014 a 2016
}

\author{
David Jesus de Almeida ${ }^{\text {; Livia Mara Gomes Pinheiro }}{ }^{2}$
}

\begin{abstract}
Resumo: A AIDS é um processo patológico causado por um vírus onde o principal meio de transmissão é por via sexual, acarretando diversas complicações na fisiologia do organismo humano. Desta maneira o elevado número de casos de vírus da imunodeficiência humana no âmbito da população idosa tem sido relacionado com o envelhecimento da população, o aumento da sobrevida de pessoas vivendo com AIDS e à entrada de medicamentos para disfunções erécteis, um fator que tem contemplado a atividade sexual das pessoas mais velhas em agregação com a desmistificação do sexo na velhice. Este trabalho tem como objetivo geral analisar a incidência de SIDA em idosos no Estado da Bahia no período de 2014 a 2016, e como objetivos específicos: verificar o número de casos de AIDS em idosos por sexo; conhecer as vias de transmissão da Aids em idosos e verificar a quantidade de casos notificados de AIDS por idade e raça de 2014 e 2016. A metodologia abordada é de maneira exploratória e quantitativa, pois trata-se de um estudo epidemiológico descritivo, cujos dados foram obtidos junto à sistema de informação SINAN saúde (SUVISA) com idosos com idade acima de 60 anos de idade portador do vírus da AIDS, de modo que o sistema de saúde contém informações que serve para apoiar as políticas de formulação e avaliação, planos e programas de saúde, facilitando o processo de tomada de decisão, a fim de contribuir para a melhoria do estado de saúde da população através das vias de dados.
\end{abstract}

Descritores: Epidemiológico. AIDS. Idosos.

\section{Elderly Epidemiology with AIDS in Bahia according to the 2014-2016 SINAN}

\begin{abstract}
AIDS is a pathological process caused by a virus where the main means of transmission is sexual, causing several complications in the physiology of the human organism. In this way, the high number of cases of human immunodeficiency virus in the elderly population has been related to the aging of the population, the increase of the survival of people living with AIDS and the entry of drugs for erectile dysfunction, a factor that has contemplated the sexual activity of older people in conjunction with the demystification of sex in old age. This study aims to analyze the incidence of AIDS among the elderly in the State of Bahia from 2014 to 2016, and to specific objectives: to verify the number of AIDS cases in the elderly by sex; to know the avenues of AIDS transmission in the elderly and to verify the number of AIDS cases reported by age and race of 2014 and 2016. The methodology is exploratory and quantitative, as it is a descriptive epidemiological study, whose data were obtained from the SINAN health information system (SUVISA) with elderly people over 60 years of age with AIDS virus, so that the health system contains information to support formulation and evaluation policies, plans and programs facilitating the decision-making process, in order to contribute to the improvement of the health status of the population through data paths.
\end{abstract}

Keywords: Epidemiology. AIDS. Seniors

${ }^{1}$ Graduando em enfermagem no $10^{\circ}$ semestre pela Faculdade Independente do Nordeste. Contato: davidalmeida14@hotmail.com;

${ }^{2}$ Enfermeira, graduada pela Universidade do Sudoeste da Bahia (UESB), pós graduada em Saúde Pública pela Universidade Estácio de SáRJ, em Ensino Superior pela FIOCRUZ, Urgência e Emergência pela FTC/ VC, Saúde Mental pela UFRJ e Mestre em Ética e Gestão pela EST/ RS; Docente na Graduação de Enfermagem e Estética e Cosmética da FAINOR-Faculdade Independente do Nordeste e dos cursos técnicos em Enfermagem do CAIC-Centro de Integração de Cursos e técnico em Prótese Dentária no Colégio Politécnico Boock. 


\section{Introdução}

O processo do envelhecimento é um artifício comum a todos os seres vivos, sendo um conhecimento compartilhado por todo ser humano, mas que nem sempre é compreendido em relação às alterações físicas, psíquicas e sociais. Assim, é fundamental não exclusivamente entender o processo do envelhecimento, como também, determinar as causas e as interferências necessárias para uma melhor qualidade de vida. O ser humano passa durante seu ciclo vital por diversas modificações, sejam elas direcionadas ao seu relacionamento com o mundo ou com sua própria história. O envelhecimento se dá devido a essas modificações, sendo elas psicológicas, biológicas e/ou sociais (LIMA; DELGADO, 2010).

Atualmente os idosos são a parte da população que mais cresce mundialmente e, com a incidência desse aumento, surgem também diversos problemas patológicos, o que acaba sendo um desafio para a saúde pública. Neste contexto espera-se que no ano 2025 a população de idosos no Brasil seja de 32 milhões. No ano 2008, o Brasil tinha 21 milhões de pessoas com 60 anos ou mais, ultrapassando a população idosa de múltiplos países europeus (IBGE, 2014).

Assim, para o Brasil, esse crescimento vem sendo um acontecimento positivo, e demostrar que a qualidade e a expectativa de vida da população vêm aumentando, mas gera grande impacto no País, já que o mesmo não está preparado para atender aos problemas que a população idosa traz, ou ter um sistema público de saúde adequado (PEREIRA; BORGES, 2010).

A AIDS é conhecida cientificamente como Síndrome da Imunodeficiência Adquirida. Surgiu no início da década de 80, sendo diagnosticado o primeiro caso no Brasil, na cidade de São Paulo, tornando-se ligeiramente uma epidemia mundial. Destaca-se que, no início da epidemia, os primeiros casos ocorreram com homossexuais e indivíduos que receberam transfusão de sangue, seguidos pelo aparecimento de casos em usuários de drogas injetáveis. Do ponto de vista epidemiológico, estima-se um crescimento populacional em idosos portadores de HIV com mais de 33,2 milhões de infectados pelo vírus no mundo. Já em relação ao Brasil, estima-se uma incidência de 3,6 para 7,1 em 100.000 habitantes e na Bahia analisa-se um aumento de 12,8\% da população referente (BRASIL, 2012). 
O surgimento da epidemia causada pelo vírus HIV- Vírus da Imunodeficiência Humana tem provocado um interesse coletivo acerca de como exercer a sexualidade. As práticas sexuais nunca foram tão visadas em discursos públicos e privados, que têm arquitetado regimes de verdade sobre como indivíduos podem, ou não, agir em grupos estimados de risco. O Governo têm pleiteado informar a população sobre o vírus e sobre como se distanciar da probabilidade de contrair o vírus. Deste modo então, tem-se patrocinado e orientado projetos de ONG - Organização Não Governamental AIDS que, das mais variantes formas, vêm apostando na diminuição da contaminação entre grupos de risco (LEITE; MOURA; BERLEZI, 2007).

Perante o exposto faz-se o seguinte questionamento: qual o perfil epidemiológico da AIDS em idosos no estado da Bahia entre 2014 e 2016? A presente pesquisa tem como objetivo geral de analisar a incidência de SIDA em idosos no Estado da Bahia no período de 2014 a 2016. Como objetivos específicos identificar o número de casos de aids por sexo, analisar o número de casos de AIDS em idosos na Bahia por raça e conhecer o número de casos de AIDS em idosos na Bahia por via de transmissão do ano de 2014 a 2015.

A SIDA é uma doença que vem crescendo entre a população idosa e existem poucos estudos sobre o tema na Bahia, por isso, despertam o interesse em buscar o conhecimento sobre a situação da população idosa portadora da AIDS no Estado da Bahia e quiçá, de contribuir de alguma forma para alertar os órgãos púbicos para criarem alternativas de investimento e de prevenção para a exposição dos idosos a situações de risco. Essa situação é também um alerta para os gestores no que diz respeito ao despertar dos idosos pela atividade sexual, após a descoberta dos medicamentos que tratam a disfunção erétil e a reposição hormonal em mulheres.

\section{Materiais e Metodos}

A presente pesquisa possui um caráter exploratório com abordagem quantitativa, pois tratar-se de um estudo epidemiológico descritivo, cujos dados serão obtidos por meio de consulta ao SINAN (Sistema de Informação de Notificação de Agravos) da SUVISA (Superintendência de Vigilância à Saúde), onde contém informações que servirão para 
subsidiar a formulação e avaliação das políticas, planos e programas de saúde, facilitando o processo de tomada de decisões, com vistas a contribuir para a melhoria da situação de saúde da população através dos dados de maneira secundários.

A pesquisa descritiva é entendida por Gil (2009) como principal descrição das características de determinada população ou fenômeno ou, então, há estabelecimento de relações entre as variáveis. Ainda lembrando que a pesquisa é descritiva porque serão descritos e analisados todos os dados epidemiológicos referentes a identificação dos casos de HIV em idosos.

É também exploratória, pois segundo Gil (2009) é desenvolvida com o desígnio de adequar uma visão geral acerca de determinado fato, tendo como desígnio principal de desenvolver, esclarecer e modificar considerações e formações de ideias e ajuda na assimilação da familiaridade com o problema. A fonte de pesquisa foi os idosos com idade superior a 60 anos conforme o Ministério da Saúde, através dos dados fornecidos pelo SINAN e das notificações entre os anos de 2014 a 2016 no estado da Bahia.

Busca de dados contidos no SINAN/ SUVISA. A SUVISA é um Sistema de Informações de Saúde onde revela dos indicadores de saúde, contendo informações epidemiológicas, morbidade e rede de assistência à saúde referentes aos recursos de Saúde transferidos aos municípios. O SINAN é o Sistema de Informação de Agravo de Notificação funcionando através de meios de notificação por fichas ou por comunicados de um determinado problema relevante de saúde, desta maneira, para implantação de programas e ações em saúde, deve-se conhecer o perfil de necessidades e a oferta de serviços existente. Para a avaliação de programas e serviços de saúde, a informação ocupa papel relevante.

A pesquisa foi realizada no SINAN investigando os casos na Bahia, onde se tem

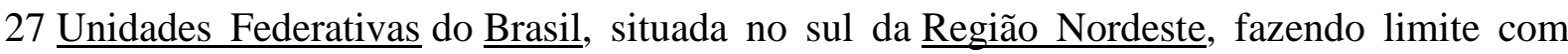
oito outros estados brasileiros e apresenta um alto índice de atendimento na rede do Sistema Único de Saúde. Possui grande economia como agropecuária e comercio, apresentando um PIB (Produto Interno Bruto) de 157,4 bilhões por ano.

Foi utilizado um roteiro para a coleta de dados do SINAN para a construção do perfil epidemiológico dos idosos com AIDS na Bahia, analisados anualmente, de 2014 a 2016. Inicialmente será pesquisado o número de casos total por ano na Bahia e depois será confeccionada uma tabela com os casos por sexo, idade, raça, óbitos e modo de transmissão. 
Este último será dividido em transmissão sexual e sanguínea, sendo que a última opção será subdividida em: uso de drogas injetáveis e transfusão sanguínea.

Diante das informações da pesquisa, o SINAN contém informações de

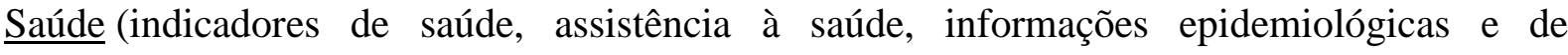
morbidade, elementos sobre a rede de assistência à saúde, estatísticas vitais, informações demográficas e socioeconômicas). Por se tratar de um banco de domínio público, não será necessário submeter o projeto ao Comitê de Ética em Pesquisa, atendendo aos aspectos éticos constantes na Resolução nº466 do ano 2012 pertencente ao CNS- Conselho Nacional de Saúde.

\section{Resultados e Discussão}

Com base nos resultados do gráfico 1, nota-se que de 2014 e 2016 houve uma certa regularidade no número de casos de AIDS notificados, porém houve um aumento no ano de 2015 permanecendo maior índice no ano de 2016.

Gráfico 1- Distribuição de casos de AIDS em idosos, segundo ano de ocorrência na Bahia de 2014 a 2016.

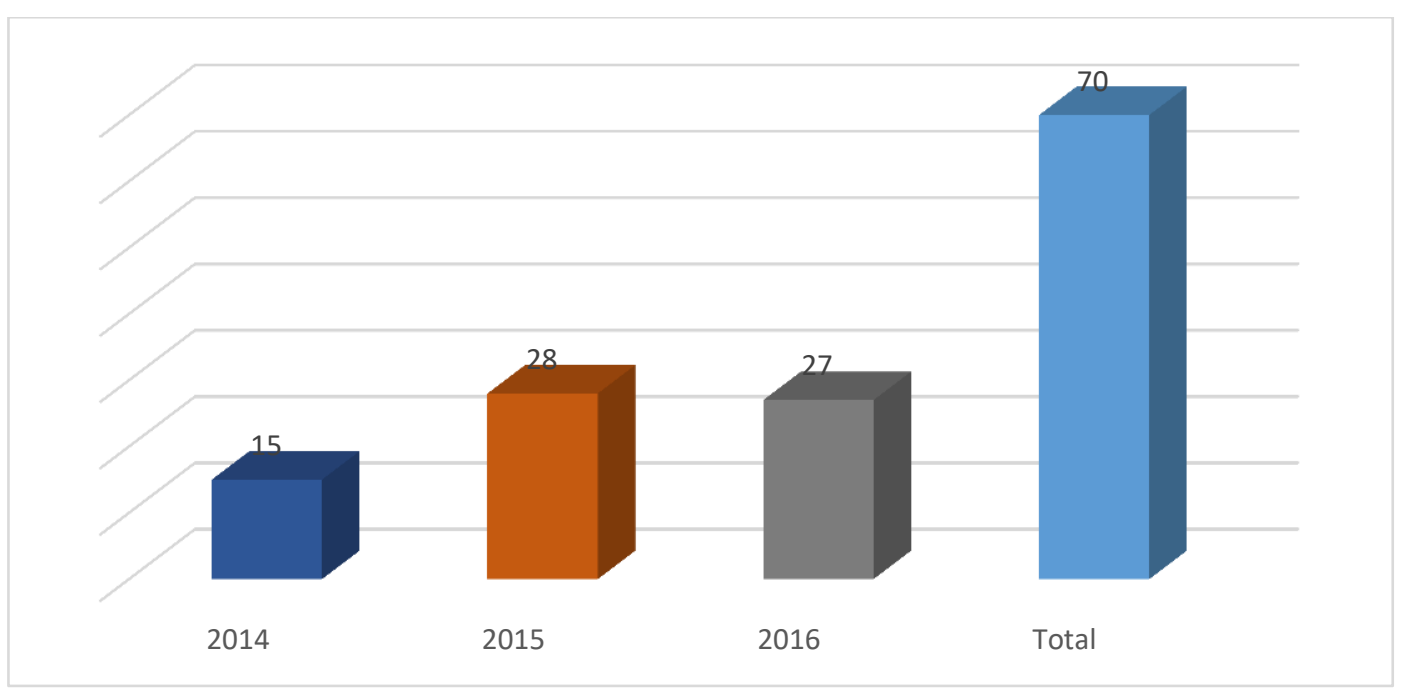

Fonte: Dados fornecidos pelo SINAN (SUVISA), 2017. 
O aumento do número de casos de AIDS em idosos nos últimos anos, pode estar associado ao aumento da expectativa de vida; ao tabu de não usar preservativos e ao uso de medicação para disfunção erétil pelos homens; além da reposição hormonal feita pelas mulheres, o que vem melhorando assim a vida sexual dessa população.

Um dos fatores essenciais que exibe esta população ao HIV/AIDS, é a carência de elementos informativos sobre o ciclo patológico, a crendice contra o uso de preservativos e a ausência de atos preventivos recuados para esse grupo. Alguns idosos se avaliam imunes ao vírus, para muitos, o conceito de adquirir HIV/AIDS em uma idade elevada não existe, porque o conhecimento sobre prevenção é indicada quase excepcionalmente aos jovens e a consciência sobre fatores de risco para idosos é baixa (CAMBRUZZI; LARA, 2012).

Diante do exposto, observa-se que esse crescimento do número de casos na Bahia, vem também acontecendo no Brasil e no mundo. Atualmente o processo epidêmico da SIDA no Brasil, tornou-se um fenômeno de elevada magnitude e extensão. Dessa maneira entre pessoas do sexo masculino, a ampliação foi de $98 \%$ na última década. Em relação ao sexo feminino, o processo epidemiológico avança como um rolo compressor havendo um crescimento de 57\% entre os anos 1991 até 2001. O número de notificações entre os idosos já supera o indicador da doença entre os adolescentes de 15 a 19 anos (CALDAS; GESSOLO, 2007).

Gráfico 2 - Distribuição do número de casos de AIDS em idosos, segundo gênero na Bahia de 2014 a 2016.

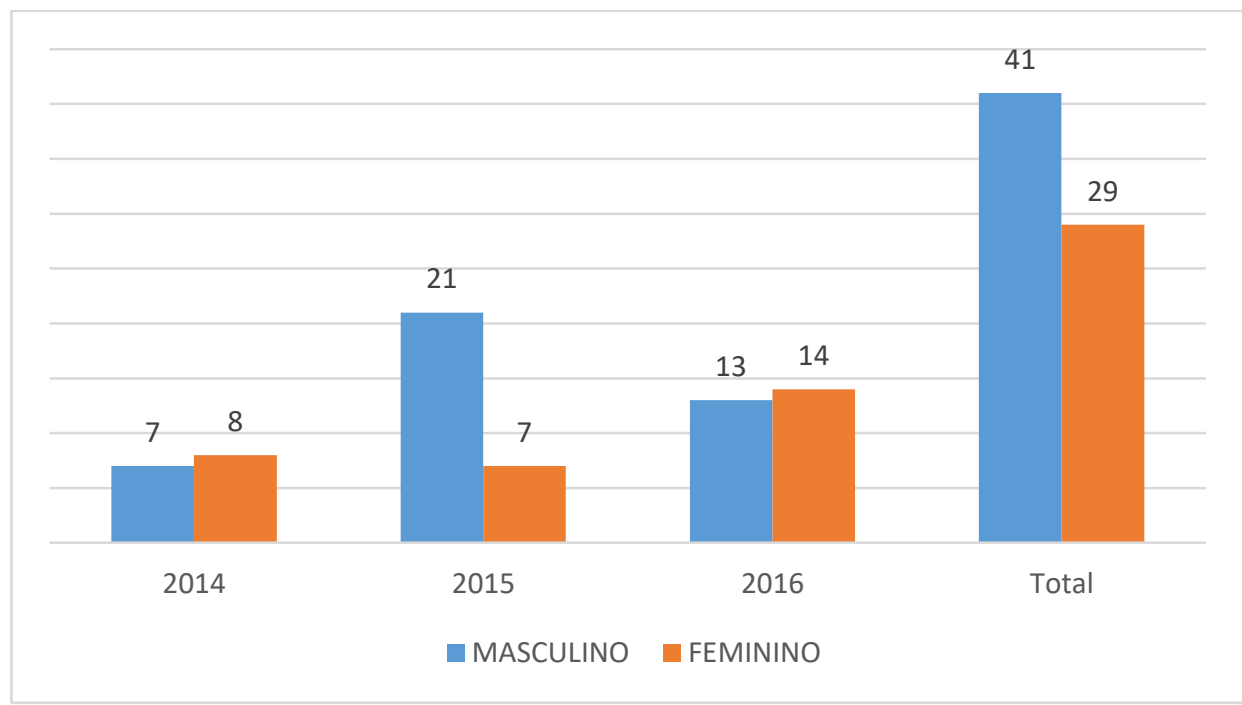

Fonte: Dados fornecidos pelo SINAN (SUVISA), 2017. 
A SIDA vem crescendo na população heterossexual e observa-se que na Bahia há uma maior incidência em homens do que em mulheres em todos os anos estudados, porém a tendência mundial é de crescimento em mulheres (BRASIL, 2007).

Outro fator a ser abordado é que os homens possuem preconceitos quanto a ida a rede de saúde e o uso adequado do preservativo (considerando que pode perder o prazer sexual), na Bahia principalmente na região nordeste o índice de infecção é maior em homens do que mulheres, um dado estatísticos diferente do Brasil onde apresenta uma contrariedade surgindo assim, o processo de feminização. Isso é confirmado por estudos epidemiológicos feitos no Brasil, dentre os fatores que podem estar contribuindo para esse novo perfil da epidemia, destacam-se o aumento da atividade sexual entre os idosos, o acondicionamento de tecnologia que melhora e prolonga a performance sexual, e a resistência em usar o preservativo (BRASIL, 2012).

Gráfico 3 - Distribuição dos números de casos de AIDS em idosos, segundo raça na Bahia de 2014 a 2016.

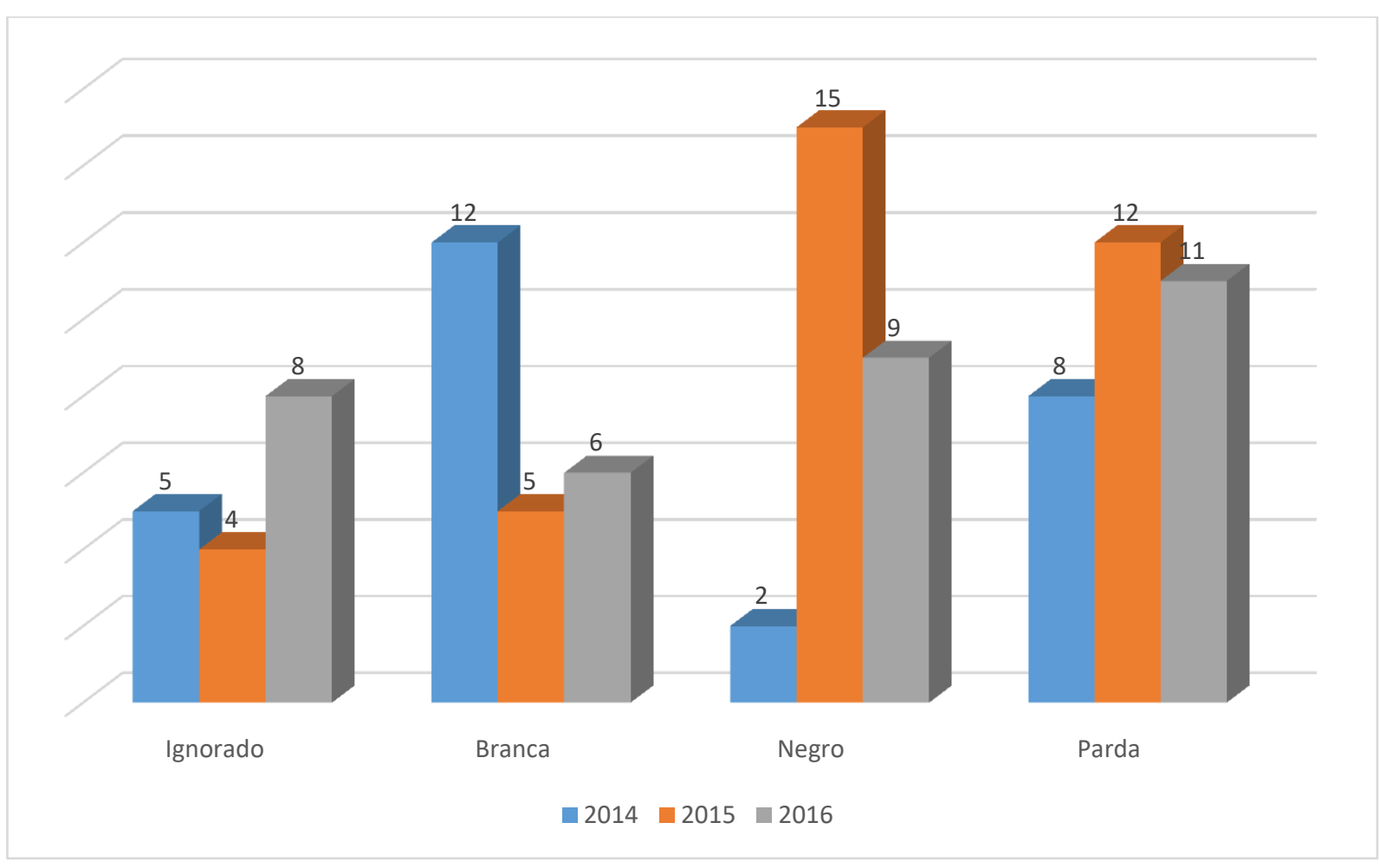

Fonte: Dados fornecidos pelo SINAN (SUVISA), 2017. 
O gráfico mostra que há um crescimento da AIDS na população parda nos anos de 2014, 2015 e 2016. Para Brasil (2008) o aumento das ações de prevenção junto aos idosos deve acentuar a construção grupal das estratégias, estimando a participação dos idosos nesses métodos, de forma que eles se destaquem como corresponsáveis pelo artefato das políticas de saúde voltados a promoção da saúde.

A SIDA não é só um processo patológico, mas sim um acontecimento social de grandes magnitudes que gera um impacto nos princípios morais, religiosos e éticos, procedimentos de saúde pública e de procedimento privado, nas questões referentes à sexualidade, ao uso de drogas e moralidade conjugal (BRASIL, 2012).

Para Okuno et al., (2014) o ato sexual de risco como o sexo não protegido e o aspectos de uso de drogas ilícitas, também pode refletir o comportamento dos adultos mais velhos e idosos. Dessa maneira, os indivíduos acima de 60 anos devem ser abarcados nas campanhas de prevenção contra o vírus da imunodeficiência adquirida. Com o aparecimento e acesso às novas drogas antirretrovirais, a utilização correta das mesmas tem possibilitado o melhoramento no controle patológico e diminuição das morbidades e da mortalidade essencialmente secundária ao processo de infecções por meio das infecções oportunistas.

Brasil (2012) afirma que por se trata do HIV, uma patologia transmissível e, até o momento incurável, cujos índices vêm se alastrando na população humana, deve-se analisar os artifícios efetivos para o seu controle e prevenção, seu conhecimento e a educação com métodos voltados para a saúde em todo o conjunto.

\section{Considerações Finais}

A AIDS é uma doença crônica, que tem aumentado entre os idosos da Bahia e do Brasil, conforme mostram os estudos no País. Embora a doença tenha reduzido entre algumas populações alvo, tem crescido entre os idosos de ambos os sexos. Os dados analisados mostram que a SIDA na Bahia atinge idosos, em sua maioria, entre 60 a 69 anos, ensino fundamental incompleto, pardos, homens e é transmitida, quase exclusivamente, por via sexual. Essas informações podem servir de subsídio para serem criadas estratégias de prevenção e tratamento da doença em idosos. 
É necessário que os gestores se debrucem sobre esse problema, que é também social, criando formas de captar essa população para a sala de aula, com programas de continuação de estudos em adultos, já existentes, bem como ampliando as ações educativas intra e extramuros na rede básica de saúde e nos programas sociais voltados para a terceira idade. Isso também pode ajudar a reduzir as desigualdades sociais que foram reproduzidas ao longo do tempo.

Há necessidade também de fazer um trabalho voltado para ambos os sexos principalmente em homens, visto que são a maioria dos casos na Bahia. As Unidades Básicas de Saúde devem estar munidas de preservativos e devem orientar a população de idosos quanto ao seu uso, pois em sua maioria não possuem o conhecimento e a prática de uso. Como a via de transmissão quase absoluta nos idosos foi a via sexual, essa distribuição regular de preservativos entre os idosos se torna fundamental.

Diante do cenário epidemiológico dos idosos com AIDS na Bahia, esse estudo, pode ser um instrumento para os profissionais analisarem a sua prática no cotidiano e direcionarem aquisições nesta extensão do conhecimento, além de oportunizarem, aos gestores públicos, a premeditação de estratégias voltadas a questão preventiva com especificidades a esta população, alertando a prevenção pelo uso adequado do preservativo. Vale ressaltar que este grupo etário carece também abordar exterioridades como comunicação com o parceiro, sexualidade benéfica em casais sorodiscordantes, luta contra o preconceito e encorajamento à ascendência do soropositivo pela família e sociedade.

Observa-se que o site das informações epidemiológicas do SINAN (SUVISA) mantém treinamento com os profissionais de saúde referentes ao preenchimento das fichas de notificação compulsória, seguindo as normas preconizadas pelo Ministério da Saúde. Cabe aos municípios estarem sempre atualizando seus profissionais de saúde em vigilância epidemiológica, para que possam estar prestando um melhor serviço de notificação, investigação, tratamento e monitoramento da SIDA, bem como, para se sentirem seguros e motivados para elaborar e levar tanto a informação quanto realizar capacitação com a população de idosos da sua área de abrangência. 


\section{Referências}

ARAÚJO, L. F; SALDANHA, A. A Aids na terceira idade na perspectiva dos idosos, cuidadores e profissionais de saúde. Academia edu, 2006. Disponível em: <http://www.academia.edu/5638469/A_Aids_na_Terceira_Idade_na_Perspectiva_dos_Idosos _Cuidadores_e_Profissionais_de_sa\%C3\%BAde_The_AIDS_in_the_Third_Age_in_the_Pers pective_of_the_Aged_ones_care-_givers_and_Profissionais_of_health>. Acesso em: 14 de Out. 2016.

BRASIL. Ministério da saúde. Prevenção E Atenção Às IST/AIDS Na Saúde Mental No Brasil: Análises, Desafios E Perspectiva. Brasília, 2008. Disponível em: <http://bvsms.saude.gov.br/bvs/publicacoes/prevencao_atencao_aids_saude_mental.pdf >. Acesso em: 25 set. 2016.

Envelhecimento e saúde da pessoa idosa, 2006. Disponível em: <http://bvsms.saude.gov.br/bvs/publicacoes/abcad19.pdf>. Acesso em 17 set. 2016.

Plano integrado de enfrentamento e feminização da epidemia de Aids e outras DST. Brasília: Ministério da Saúde, 2007. Disponível em: <http://bvsms.saude.gov.br/bvs/publicacoes/plano_feminizacao_final.pdf >. Acesso em 29 de Maio de 2015.

Uma análise da incidência dos casos de AIDS por faixa etária. Boletim Epidemiológico AIDS. Brasília: Ministério da Saúde, Ano I - $\mathrm{n}^{\mathbf{0}} 01$ até semana epidemiológica 52 $\quad$ a dezembro de 2012. Disponível em: <http://www.aids.gov.br/sites/default/files/anexos/publicacao/2012/52654/boletim_2012_fina 1_1_pdf_21822.pdf >. Acessado em 29 de maio de 2015.

BORBA, R. Intertext Sexualidade: A construção discursiva de identidades na prevenção de dst/aids entre travestis. Trabalho Línguas Aplicadas. vol.49 no.1 Campinas Jan./June 2010. Disponível em: <http://www.scielo.br/scielo.php?script=sci_arttext\&pid=S010318132010000100003>. Acessado em 09 Abril de 2015.

CAMBRUZZI, C; LARA, M. G; HIV/AIDS Em Idosos Brasileiros. Revista LConhecimento Online, ano 4. v1. Março de 2012. Disponível em: $<$ http://www.feevale.br/site/files/documentos/pdf/58664.pdf >. Acessado em: 19 de Fevereiro de 2015

CALDAS, J. M. P; GESSOLO, K. M. AIDS Depois dos 50: Um novo desafio para as Políticas de saúde pública, 2007. Disponível em:< http://repositorioaberto.up.pt/bitstream/10216/56540/2/89657.pdf >. Acessado em: 17 maio 2015.

GIL, A. C. Como Elaborar Projetos de Pesquisa - 5. ed. - São Paulo, Atlas, 2009. 
GODOY, V et al., O perfil epidemiológico da AIDS em idosos utilizando sistemas de informações em saúde do DATA SUS: realidades e desafios, 2008. Revista de DST Brasileira de Doenças Sexualmente Transmissíveis, 2008; 20(1): 7-11. Disponível em: <http://www.dst.uff.br//revista20-1-2008/1.pdf>. Acessado em 06 de maio de 2015.

GIR, E et al. Medidas Preventivas Contra A Aids E Outras Doenças Sexualmente Transmissíveis Conhecidas Por Universitários Da Área De Saúde, Revista LatinoAmericana em Enfermagem - v. 7 - n. 1 - p. 11-17 - janeiro 1999. Disponível em:< http://www.scielo.br/pdf/rlae/v7n1/13444.pdf>. Acesso em: 19 Abril de 2015.

GOMES, S; SILVA, C. Perfil dos idosos infectados pelo HIV/AIDS: uma revisão. Vittalle, Rio Grande, 20(1): 107-122, 2008. Disponível em: <http://www.seer.furg.br/vittalle/article/viewFile/954/398>. Acessado em 20 de maio de 2015.

GURGEL, S. N et al. Vulnerabilidade Do Idoso Ao Hiv: Revisão Integrativa.

Revista de enfermagem da UFPE on line., Recife, 8(supl. 1):2487-93, jul., 2014. Disponível em <http://webcache.googleusercontent.com/search?q=cache:nvNe8ki3qLAJ:www.revista.ufpe.b r/revistaenfermagem/index.php/revista/article/viewFile/6216/pdf_5742+\&cd=1\&hl=ptBR\&ct=clnk\&gl=br>. Acessado em 29 de Maio de 2015.

IBGE. Instituto Brasileiro de Geografia e Estatística. [online] (2014). Brasília [s.d.]. Disponível em: http:// www.ibge.com.br. Acessado em: 08 de setembro de 2014.

LAZZAROTTO, A. R. et al. O conhecimento de HIV/aids na terceira idade: estudo epidemiológico no Vale do Sinos, Rio Grande do Sul, Revista de Ciências e Saúde Coletiva, v. 13, n. 6, p.1833-1840, dez. 2008. Disponível em: $<$ http://www.scielo.br/scielo.php?script=sci_arttext\&pid=S1413-81232008000600018>. Acesso em: 10 abril 2015.

LEITE, M. T; MOURA, C; BERLEZI, E. M. Doenças sexualmente transmissíveis e HIV/AIDS na opinião de idosos que participam de grupos de terceira idade. Rev. Bras. Geriatr. Gerontol, 10(3), 2007. Disponível em: $<$ http://revista.unati.uerj.br/scielo.php?script=sci_arttext\&pid=S180998232007000300007\&lng=pt\&nrm=iso>. Acesso em 12 Abril de 2015.

LIMA, A. P; DELGADO, E. I. A Melhor Idade Do Brasil: Aspectos Biopsicossociais Decorrentes Do Processo De Envelhecimento. Ulbra e Movimento (REFUM), Ji-Paraná, v.1 n.2 p76-91., set./out. 2010.2 Disponível em: <http://revista.ulbrajp.edu.br/ojs/index.php/actabrasileira/article/viewFile/630/142>. Acesso em 30 Fevereiro de 2015.

MINAYO, Maria Cecília de Souza (Org.). Pesquisa Social: Teoria, Método e Criatividade. $21^{\circ}$. Ed. Petrópolis: Vozes, 2001. 
MIGUEL, A. AIDS entre os idosos brasileiros. Medicina geriátrica, geriatria e gerontologia, 2009. Disponível em: <http://www.medicinageriatrica.com.br/2009/05/26/aids-entre-osidosos-parte-3/>. Acesso em 06 de maio de 2015.

OKUNO, M. F. P et al., Qualidade de vida de pacientes idosos vivendo

com HIV/AIDS. Cad. Saúde Pública, Rio de Janeiro, 30(7):1551-1559, jul, 2014. Disponível em: <http://www.scielo.br/pdf/csp/v30n7/0102-311X-csp-30-7-1551.pdf>. Acesso em 29 de maio de 2015.

PAPALÉO NETTO, Matheus. Tratado de Gerontologia. $2^{\text {a }}$. ed., rev. e ampl. São Paulo: Editora Atheneu, 2007.

PEREIRA, G. S; BORGES. C. I. Conhecimento sobre HIV/ AIDS de participantes de um grupo de idosos, em Anápolis-Goiás. Esc Anna Nery Rev Enferm 2010; 14:720-5. Disponivel em: <http://www.scielo.br/scielo.php?script=sci_arttext\&pid=S141481452010000400010>. Acesso em 18 de Maio de 2015.

SALDANHA, A. A. W; FELIX, S. M. F; ARAÚJO, L. F. Representações sobre a Aids na velhice por coordenadoras de grupos da terceira idade. Psico-USF, v. 13, n. 1, p. 95-103, jan./jun, 2008. Disponível em: <http://www.scielo.br/pdf/pusf/v13n1/v13n1a12.pdf>. Acesso em 06 de Maio de 2015.

SERRA, A et al. Percepção de vida dos idosos portadores do HIV/AIDS atendidos em centro de referência estadual. Saúde em Debate. Rio de Janeiro, v. 37, n. 97, p. 294-304, abr./jun. 2013. Disponível em:〈http://www.scielo.br/pdf/sdeb/v37n97/v37n97a11.pdf>. Acesso em: 16 de Fevereiro de 2015.

TAVARES, F. M. B. Apontamentos sobre o conceito de qualidade de vida: revisões, cruzamentos e possibilidades críticas. Revista Brasileira de Qualidade de Vida 2011; 3:2332. Disponível em: <https://periodicos.utfpr.edu.br/rbqv/article/view/1067>. Acesso 10 de Fevereiro de 2015.

TORRES, C. C, et al., Representações sociais do hiv/aids: buscando os sentidos construídos por idosos. Revista de Pesquisa Cuidados Fundamentos. online, 2012. dez. (Ed.Supl.):121128. Disponível em:

<http://www.seer.unirio.br/index.php/cuidadofundamental/article/view/1960/pdf 532>.Acess o em 10 de Janeiro de 2015.

VALENTINI, M; RIBAS, K. Terceira idade: tempo para semear, cultivar e colher, Revistas Analecta, v4n1, 2003. Disponível em: < https://www.sescrs.com.br/cre/boletim/_ano9_n01.htm>. Acesso em: 06 de abril de 2015.

WENDT, G. AIDS e envelhecimento: repercussões na saúde pública. Revista do Sistema Integral de Saúde. Porto Alegre-RS, 2010. Disponível em: 
Id on Line Revista Multidisciplinar e de Psicoloqia

Id on Line Multidisciplinary and Psycology Journal

<http://www.sissaude.com.br/sissaude/userfiles/AIDS\%20e\%20envelhecimento.pdf $>$. Acessado em 12 de Maio de 2015.

ZORNITTA, M. Os novos idosos com AIDS: Sexualidade e Desigualdade à Luz da Bioética, Dissertação de apresentação a título de mestre em ciências na área de saúde pública, 2008. Disponível em: <http://www5.ensp.fiocruz.br/biblioteca/dados/txt_978052416.pdf>. Acessado em 06 de abril de 2015.

ZIMERMAN, G. I. Velhice: Aspectos Biopsicossociais. Porto Alegre: ARTES MÉDICAS, 2000 .

Como citar este artigo (Formato ABNT):

ALMEIDA, David Jesus de; PINHEIRO, Lívia M. G.. Epidemiologia dos Idosos com AIDS na Bahia segundo o SINAN de 2014 a 2016. Id on Line Revista Multidisciplinar e de Psicologia, 2017, vol.11, n.37, p. 640-652. ISSN: 1981-1179.

Recebido: 21/09/2017

Aceito: $25 / 09 / 2017$ 